\title{
(C. COBENGE \\ USO DA FILOSOFIA E METODOLOGIAS ATIVAS COMO INSTRUMENTO FACILITADOR DA APRENDIZAGEM DE INOVAÇÃO E TECNOLOGIA PARA ESTUDANTES DE ENGENHARIA
}

DOI: 10.37702/2175-957X.COBENGE.2021.3480

AGNES CRISTINA OLIVEIRA MAFRA - AGNESCMAFRA@ufam.edu.br UNIVERSIDADE FEDERAL DO AMAZONAS

Rua vinte e nove de agosto 296

69800-000 - Humaitá - AM

Luan Claiton de Moraes Marostegan - luanmoraes.mail@gmail.com Universidade Federal de Mato Grosso

Avenida Porto Alegre 1900

78894-036 - Sorriso - MT

Ana Cláudia Franca Gomes - anafrancca@yahoo.com.br UFMT

Rua 13877

78068-425 - Cuiabá - MT

Resumo: $O$ presente estudo apresenta e discute os aspectos estruturais e formativos do componente curricular de inovação e tecnologia. Através de metodologias ativas de ensino aliados ao Mito da Caverna de Platão, iniciativa de trabalho no Ensino Superior realizada em âmbito dos cursos de Engenharias. Aspectos como criatividade, senso crítico e socialização foram desenvolvidas com êxito nas etapas propostas.

Palavras-chave: Ensino-aprendizagem. Filosofia. Ensino superior. 


\section{INTRODUÇÃO}

O processo de ensino-aprendizagem envolve uma série de desafios, do desconhecimento profundo a respeito, do mundo das ideias, à relutância em aceitar alterações em nosso universo prático e físico. O ensino de inovação e tecnologia para futuros engenheiros tem uma complexidade maior pois, a construção de algo inovador requer a percepção da realidade atual e da capacidade de imaginação ou alusão de uma realidade do estudante (BARBOSA \& MOURA, 2014).

Segundo Paiva et al. (2016), o ensino real não se limita à habilidade de dar aulas, ou seja, reduzido de modo mecânico e acrítico, mas sim como a necessidade do saber reconstruído pelo próprio sujeito. Para tal, é fundamental desenvolver o aprendizado através de abordagens ativas que valorizem as experiências internas dos alunos e assim fazer com que os discentes criem conexões com conhecimentos anteriores que possuam (SILVA \& CECÍLIO, 2007; BARBOSA \& MOURA, 2014).

\subsection{Fundamentação teórica}

A concepção de mundo real e mundo de ideais foi descrita na obra de Platão "A República" (380 e 370 a.C), em que se narra um diálogo de Sócrates e Glauco a respeito da situação em que se encontra a humanidade através de metáforas. Platão utilizando linguagem alegórica narrou em seu livro VII "O Mito da Caverna ou Alegoria da Caverna", a presença de escravos acorrentados em uma caverna de tal forma que eles apenas conseguiam enxergar sombras projetadas em uma parede através a iluminação de uma tocha de fogo na entrada da caverna, assim como mostra a Figura 1. Nessa condição, os escravos de costas para a entrada da caverna percebiam os movimentos das sombras do que estava acontecendo no mundo exterior. Certo dia, um dos acorrentados livra-se das amarras e sai para o mundo exterior, onde encontra vida, cor, luz e calor. Maravilhado após enxergar a realidade, o prisioneiro retorna para relatar aos outros prisioneiros o que viu. Inconformados, os outros escravos ameaçam matá-lo. Sem outra condição, o liberto cria fantasias e mitos para justificar as aparências, procurando assim poupar a sua vida. Platão tenta, dessa forma, mostrar o quanto os homens estavam presos a imagens, sombras ou preconceitos e superstições.

Figura 1 - Alegoria da Caverna de Platão.

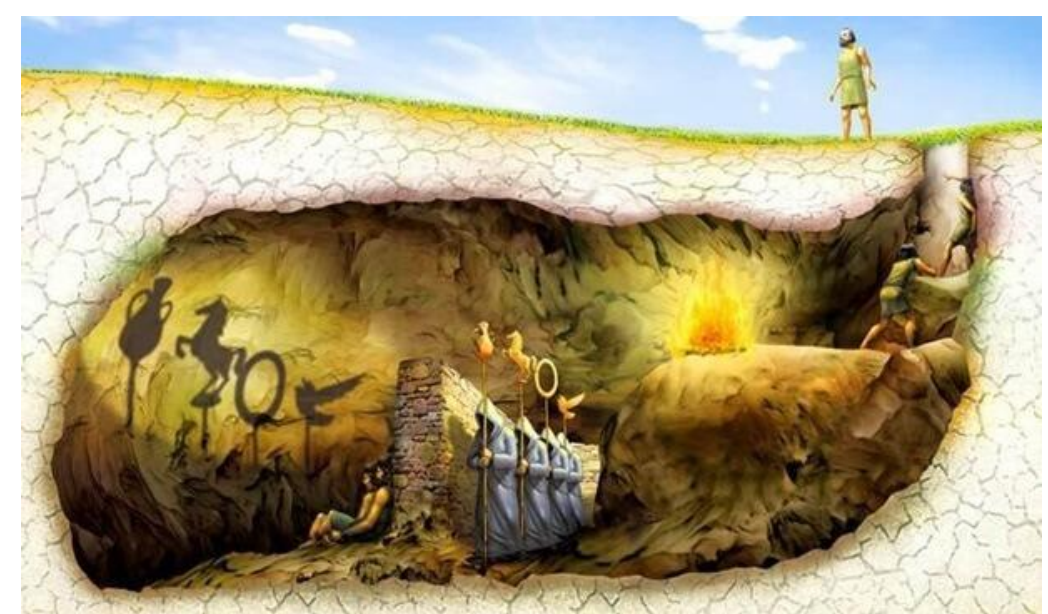

Fonte: Queirós (2008). 
Trazendo a alusão do Mito da Caverna para o dia a dia, a caverna pode representar o comodismo e/ou a alienação em que estamos envolvidos (OLIVEIRA, 2015).

O mundo exterior pode fazer a alusão ao mundo real, que tem a ver com a racionalidade e conhecimento. Vicente Fideles de Ávila indica que a educação "[...] para Platão, é muito mais do que preparação para a vida e, ainda, mais que formação, com implicações no âmbito do armazenamento, da formulação no conhecimento científico e cultural e, inclusive, na da aquisição e adoção de maneiras de agir axiologicamente válidas" (1998, p. 165). Enquanto Antônio Nunes Malveira "[...] chama atenção para a educação dos jovens que mais tarde seriam os guardiões de cidade, a fim de que eles soubessem discernir entre justiça e injustiça" (2010, p. 25).

Segundo Barbosa e Moura (2014) um futuro engenheiro deve ter as habilidades de pensar, raciocinar, observar, refletir, entender e combinar para tal, aplicar metodologias ativas de aprendizagem como aulas de laboratório, oficinas, tarefas em grupo, trabalhos em equipe dentro e fora do ambiente escolar, visitas técnicas e desenvolvimento de projetos, tornam o ambiente de aprendizagem ativo e assim, gera-se a atitude ativa do discente ou inteligência. Para Platão a educação "[...] consiste na formação correta que mais intensamente atrai a alma da criança, durante a brincadeira para o amor daquela atividade da qual, ao se tornar adulto terá que deter perfeito domínio" (1999, p. 92). Corroborando com a teoria de Platão e com o desejo da formação de um engenheiro ativo, autores apontam o uso de maquetes ou protótipos como técnica de ensino e aprendizagem para realizar a difusão do conhecimento científico, uma vez que são abstrações da teoria em forma física, ou seja, um link entre a atividade prática e o conceito envolvido (GILBERT, BOLTER, HELDER, 2000).

Com base no uso da alegoria de Platão, os alunos do primeiro semestre do curso de Engenharia de uma universidade no estado de Mato Grosso, desenvolveram ao longo de três aula um projeto baseado em metodologia ativa para a disciplina de Inovação e Tecnologia. $O$ projeto propôs para esses alunos a pesquisa, discussão, representação teatral e construção de maquetes de um mundo ideal, a partir de papel e isopor, com o objetivo de possibilitar ao futuro engenheiro: I) aprender sobre o conceito de realidade e idealidade; II) refletir sobre a prática e a importância do uso responsável dos recursos naturais disponíveis em nosso dia a dia; III) utilizar maquetes como estratégia de demonstração de futuros projetos de engenharia. Além desses tópicos também se buscou o desenvolvimento da oralidade e integração do corpo discente através de discussões, representações teatrais e a apresentação das maquetes.

A partir deste projeto, tentamos responder as seguintes perguntas: quais as contribuições do uso dessa estratégia no desenvolvimento da criatividade dos futuros engenheiros?

\section{MATERIAIS E MÉTODOS}

Os métodos de aprendizagem ativas utilizados para a realização do presente trabalho provêm da aplicação de um projeto baseado no livro VII da República de Platão "O Mito da Caverna ou Alegoria da Caverna", aplicado à 50 alunos de primeiro semestre de engenharias no estado do Mato Grosso.

Este projeto foi aplicado em três aulas de duas horas e realizou-se em três partes. Na primeira fase foi solicitado ao discente que fizesse uma resenha sobre o Mito da Caverna explicando com suas palavras a alegoria de Platão. $\mathrm{Na}$ aula seguinte o corpo discente trouxe suas resenhas e de posse delas, os discentes foram divididos em 5 grupos de 10 alunos. Nesses grupos eles discutiram o que acontecia na Alegoria de Platão e fazendo um paralelo com o mundo atual eles foram solicitados a fazer um teatro que representaria a mesma mensagem do Mito da Caverna. 
Na sequência o corpo discente ainda em suas equipes, foram incitados a pensar em que posição "eles" estariam na caverna de Platão, para tal, propôs-se uma representação teatral na qual os alunos fazendo uma alusão aos dias atuais representariam o Mito de Platão.

$\mathrm{Na}$ terceira aula os estudantes foram questionados que se existisse um outro mundo ideal e de infinitas possibilidades, como seria esse mundo. A partir deste questionamento a docente propôs a construção de maquetes da cidade e/ou protótipos de objetos que pudessem estar nesse mundo de infinitas possibilidades. Por fim ocorreu uma exposição final do trabalho com diálogo sobre as impressões pessoais adquiridas durante o período de construção e idealização da maquete.

\section{RESULTADOS E DISCUSSÃO}

A experiência iniciou-se com um encontro em que foi solicitada a pesquisa sobre o Mito da Caverna de Platão. Para colaborar com a busca conteúdos foram expostos vídeos e textos no Ambiente Virtual de Aprendizagem (AVA), antes do encontro presencial, para que pudessem ser acessados e explorados de maneira mais significativa durante a aula que sempre iniciava com uma parte expositiva e depois promovida uma prática. Essa proposta foi baseada nos processos de ensino invertido (Flipped Classroom) criada pelos professores norte-americanos de Química, Jonathan Bergmann e Aron Sams, em que o docente oportuniza um momento de estudo ou pesquisa antecipadamente em casa do tema que ainda será abordado em aula (BISHOP \& VERIEGER, 2013; PAIVA et al, 2016; ROTELLAR \& CAIN, 2016).

$\mathrm{Na}$ aula subsequente, os alunos estavam de posse de suas resenhas resultado de suas pesquisas e constatações sobre o Mito da Caverna de Platão. A docente expôs um vídeo disponível na plataforma YouTube do projeto Casa do Saber com o Professor de Filosofia Maurício Marsola, sobre o Mito da Caverna com o intuito de iniciar a discussão sobre a temática de ideal e real.

$\mathrm{Na}$ sequência dividiu-se a turma em equipes para que todos os discentes tivessem a oportunidade de trocar de ideais e argumentações assim como, dividir o conhecimento pesquisado em suas resenhas.

Neste momento a docente passou em cada equipe para se certificar que a discussão estava sendo feita, propôs-se três questões para as equipes neste momento: $1^{\circ}$ ) Quem é você na caverna de Platão? $2^{\circ}$ ) Como você agiria se fosse o escravo que escapou? $3^{\circ}$ ) Por que ninguém que passava fora da caverna interagia com quem estava dentro da caverna? Os discentes responderam à essas questões em que, quase que $100 \%$ dos alunos sentiam que eram os escravos acorrentados na alegoria da caverna. A maior parte da turma (80\%) alegou que não retornaria à caverna caso conseguisse de soltar das amarras, mas que tentaria, de alguma maneira, soltar seus companheiros de prisão. Segundo os alunos, o motivo pelo qual os transeuntes do entorno da caverna não interagiam com os prisioneiros, era porque eles não se enxergaram. Como se os escravos e os transeuntes estivessem em "mundos diferentes". As repostas do alunado correspondem às inúmeras interpretações sobre a Alegoria de Platão (RODRIGUES, 2007; QUEIRÓS, 2008).

José João Neves Barbosa Vicente aponta para o fato de que na Alegoria da Caverna "[...] existem questões sobre conhecimento, metafísica, moral, educação, estética, religião, mas todas elas são discutidas em vista a política - cidade ideal ou justa" (2014, p. 215). A docente nesse momento, teve a intenção de fazer com que os discentes questionassem suas realidades, indo além do pensamento comum para que assim cada aluno tivesse a experiência de "libertar suas correntes". 
$\mathrm{Na}$ aula subsequente, a docente fez a solicitação de que cada equipe fizesse uma representação teatral sobre a alegoria da caverna nos dias atuais, com assuntos quotidianos. Os estudantes tiveram dificuldades de pensar nas inúmeras vezes que em nosso dia a dia temos momentos de "insight" ou de clara percepção da realidade a nossa volta. Alguns grupos fizeram representação de salas de aulas com alunos aprendendo diferentes temas, outros grupos representaram conversas com familiares e outros alunos relataram situações de injustiça social. Em todos os casos os discentes sempre se viam como "acorrentados às situações de ignorância" e os principais "agentes de confundimento"da realidade seriam as mídias como televisão e redes sociais, atreladas ao preconceito inserido na sociedade. Para José João Neves Barbosa Vicente "[...] A única solução encontrada por Platão, capaz de resolver essa confusão a respeito da justiça e de muitas outras coisas, é a educação: a experiência da caverna reflete, essencialmente, a natureza humana 'relativamente à educação ou à sua falta'” (2014, p. 220).

Com o término desta segunda aula, solicitou-se aos alunos que trouxessem para a próxima aula, jornais, tesoura, cola e fita adesiva. Por fim na terceira aula em que se explorou o Mito da Caverna de Platão, os discentes foram indagados a pensar como seria um "mundo" ideal e tecnológico que supostamente estaria atrás das pedras da caverna da alegoria, a Figura 2 foi utilizada como gatilho para os estudantes. E ainda em suas equipes, foram solicitados a fazer maquetes ou protótipos de itens tecnológicos que existiria neste mundo ideal e tecnológico. Essa aprendizagem baseada em projetos foi aceita e concluída com sucesso pelo alunado, tal qual mostra a Figura 3. Estrategicamente essa etapa foi colocada por último pois, pensava-se que após o rompimento dos paradigmas sociais (nas aulas 1 e 2) e o alunado teria mais chance de ser criativo, e, assim, se entregar às muitas possibilidades de maquetes e protótipos.

Silva e Cecílio definem que "[...] a formação de engenheiros tem um ou outro modelo, conforme se estabelecem os perfis das transformações sociais e econômicas, seja para a formação de quadros da indústria, seja para os de gestão de empresas, em consonância com as mudanças na economia, desde a Revolução Industrial do século XIX (2007, p.06). Porém, pesquisas recentes demonstram que o futuro engenheiro precisa ter atribuições técnicas, econômicas e socio-administrativas (LAUDARES \& RIBEIRO, 2000; PEIXOTO et al. 2005; KERSTEN, 2018).

O uso de metodologias ativas nas Engenharias tem indícios de expansão pelos cursos e vêm como alternativa para contemplar o tópico "socio-administrativas", conforme mostra a pesquisa de Barbosa e Moura (2014).

Figura 2 - Alegoria da Caverna de Platão - A fuga. 


\section{COBENCE de Educação em Engenhari $2021 \mid \begin{aligned} & \text { de Educaçáo } \\ & \text { da ABENGE }\end{aligned}$

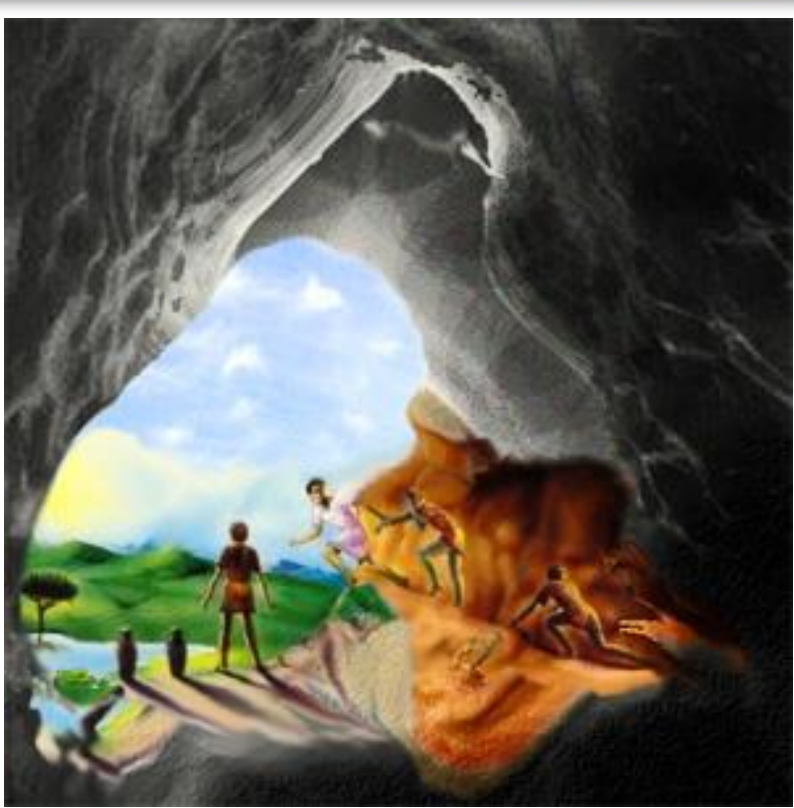

Fonte: Queirós (2008).

Figura 3 - (a) Maquete proposta pelos discentes para um mundo ideal e tecnológico. (b) Protótipos de equipamentos tecnológicos de um mundo imaginário e ideal. (c) Material utilizado para a produção das maquetes e protótipos.

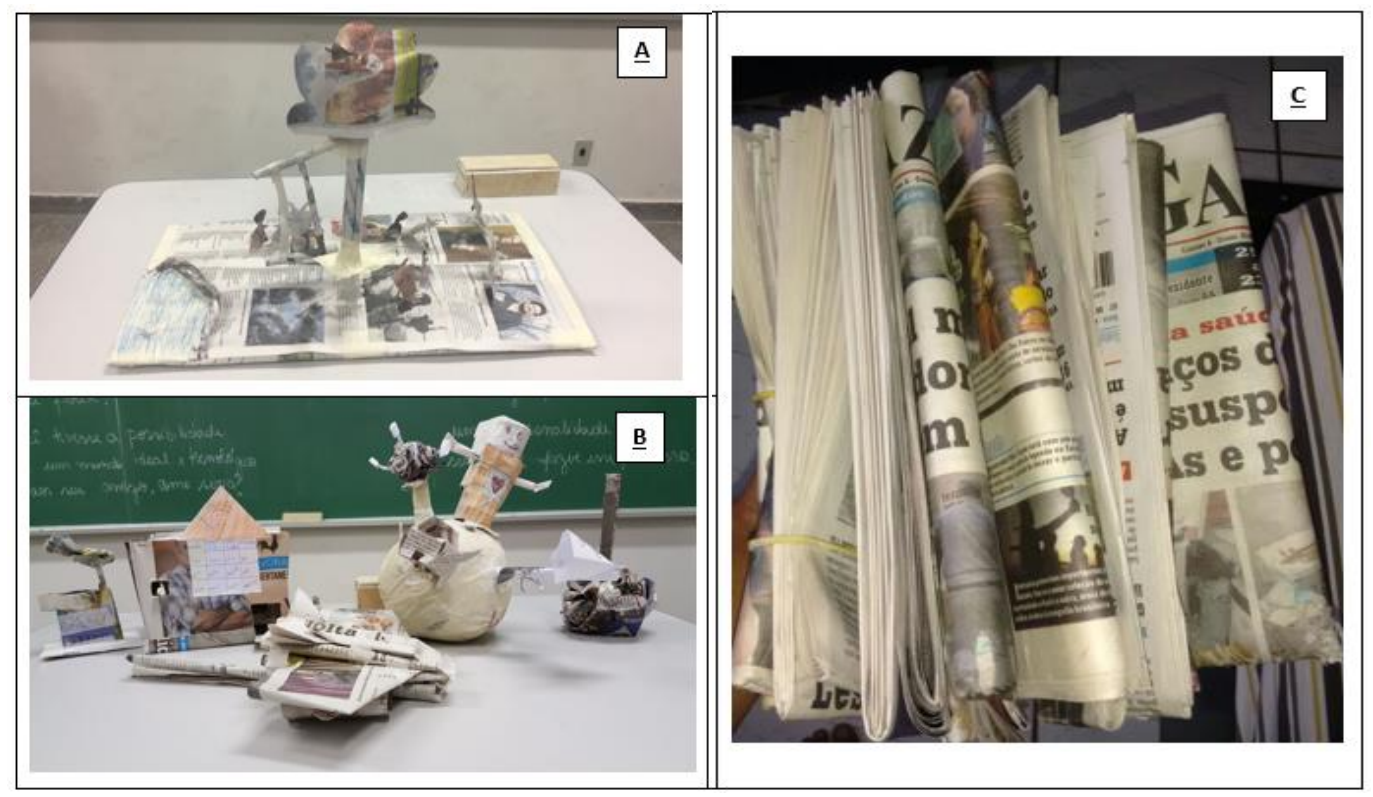

Com todas as três etapas desse projeto que envolvia a Alegoria da Caverna de Platão, intencionou-se conduzir o desenvolvimento humanístico, criativo e social dos futuros engenheiro, tal qual seria necessário para formar um engenheiro da quarta revolução industrial. Obviamente, as práticas baseadas em metodologias ativas exigem momentos de reflexão para a melhoria dos procedimentos didáticos frente aos entraves apresentados, e processos de auto avaliação e replanejamento. Certamente a habilidade de comunicação do docente assim como, a liderança e observação constante do alunado. O processo do ensino ativo é não fácil, mas muito recompensador uma vez que, os discentes saem das etapas de ensino motivados e modificados. 


\section{CONCLUSÕES}

Através da caracterização da proposta e de reflexões em torno do Mito da Caverna de Platão, buscou-se contemplar os desafios e as possibilidades da alegoria relatada. A alegoria é uma maneira para expressar as ideias de percepção do mundo e o lugar em que cada um se encontra nele.

Verificou-se que a proposta pedagógica de construção de resenhas, discussões, apresentações teatrais e maquetes aqui apresentadas se desenha fortemente alicerçada na possibilidade concreta de mudança na forma de pensar e fazer a prática pedagógica. Entende-se esse tipo de metodologia ativa como uma oportunidade de demonstrar uma ferramenta para aprendizagem em sala de aula, que contribui para o maior envolvimento do alunado.

O mercado de trabalho de um profissional de engenharia exige que ele tenha condições de produzir e ampliar o conhecimento passado em sala de aula. $E$ através deste trabalho atingiu-se uma mudança de paradigma na relação professor-aluno bem como, no processo de ensino-aprendizagem e inovação/tecnologia. Por fim, acredita-se que a experiência foi extremamente desafiadora e acima de tudo formativa para a docente e acadêmicos do curso de engenharia.

\section{REFERÊNCIAS}

ÁVILA, V. F. República de Platão segundo Werner Jaeger: Teoria de Estado ou Estudo sobre Educação. Multitemas (UCDB), Campo Grande, v. 10, p. 155-166, 1998.

BARBOSA, E. F.; MOURA, D.G. Metodologias ativas de aprendizagem no ensino de engenharia. In: International Conference on Engineering and Technology Education, 2014, Cairo. Anais. Cairo. Disponível em:

http://www.tecnologiadeprojetos.com.br/banco objetos/\%7BAE67192D-A4A1-49C6-936A7D95030BC2E7\%7D Metodologias\%20Ativas\%20no\%20ensino\%20de\%20Engenharia\% 20Artigo\%20Congresso\%20Intertech.pdf.

BISHOP, J. L.; VERLEGER, M. A; The Flipped Classroom: A Survey of the Research. In: American Society for Engineering Education, 2013. Atlanta. Anais. Atlanta. Disponível em: https://www.researchgate.net/publication/285935974 The flipped classroom A survey 0 f the research/citation/download.

GILBERT, J.; BOULTER, C.; ELMER, R. Positioning Models in Science Education and In Design and Technology Education. Developing Models in Science Education, 3-17, 2000. <https://doi.org/10.1007/978-94-010-0876-1_1> .

KERSTEN, S. Approaches of engineering pedagogy to improve the quality of teaching in engineering education. In: DRUMMER, J.; HAKIMOV, G.; JOLDOSHOV, M.; KÖHLER, T.; UDARTSEVA, S. Vocational Teacher Education in Central Asia. 1 ed. Cham: Springer, 2018. p. 129-139. <https://doi.org/10.1007/978-3-319-73093-6_14>.

LAUDARES, J.B.; RIBEIRO, S. Trabalho e formação do engenheiro. Revista brasileira de estudos pedagógicos, Brasília, v. 81, n. 199, p. 491-500, 2000. <https://doi.org/10.24109/2176-6681.rbep.81i199.967>. 
LAZARINI, A. Platão e a educação: um estudo do livro VII de A República. Dissertação (Mestrado) - Programa de Pós-Graduação em Educação. Universidade Estadual de Campinas. Campinas-SP, 2007. Disponível em: <http://repositorio.unicamp.br/handle/REPOSIP/252980>. Acesso em 27 de maio de 2021.

MALVEIRA, A.N. A educação na República de Platão. Revista da Academia Brasileira de Filologia, n. 7, 2010.

OLIVEIRA, J. A paideia grega. A formação omnilateral em Platão e Aristóteles. 2015. Tese (Doutorado) - Programa de Pós-Graduação em Educação. Universidade Federal de São Carlos, São Carlos-SP, 2015. Disponível em:

<https://repositorio.ufscar.br/handle/ufscar/2370?show=full>. Acesso em 27 de abril de 2021.

OSBORNE, R.J.; GILBERT, J.K. A technique for exploring students' views of the world. Physics Education, v. 15, n. 6, p. 376, 1980.

PAIVA, M.R.F.; PARENTE, J. R. F.; BRANDÃO, I. R.; QUEIROZ, A. H. B. Metodologias ativas de ensino-aprendizagem: revisão integrativa. Sanare Sobral, v. 15, n. 2, p.145-153, 2016.

PEIXOTO, J.A.A. et al. A visão da performance frente às demandas de mudança do perfil profissional do engenheiro. In: Anais do Congresso Brasileiro de Ensino de Engenharia. 2005.

QUEIRÓS, A. J. V. Os bastidores da caverna de Platão (entrelinhas de uma alegoria).O que nos faz pensar, n. 24, p. 95-115, out. 2008

ROTELLAR, C.; CAIN, J. Research, Perspectives, and Recommendations on Implementing the Flipped Classroom. American Journal of Pharmaceutical Education, v. 80, n. 2, 2016. 10.5688/ajpe80234.

RODRIGUES, E. M. Um breve estudo sobre a educação na República de Platão. 2007. Dissertação (Mestrado). Programa de Pós-Graduação em Educação. Universidade Estadual de Campinas. Campinas-SP, 2007. Disponível em: http://repositorio.unicamp.br/jspui/handle/REPOSIP/252900. Acesso em 27 de abril de 2021.

SILVA, L.P.; CECÍLIO, S. A mudança no modelo de ensino e de formação na engenharia. Educação em Revista, Belo Horizonte. v. 45. p. 61-80. 2007

VICENTE, J. J. N. B. Justiça e educação na República de Platão. Saberes: Revista interdisciplinar de Filosofia e Educação, Natal, v. 1, n.9, p. 82-92, 2014. 


\section{USE OF PHILOSOPHY AND ACTIVE METHODOLOGIES AS A FACILITATING INSTRUMENT FOR LEARNING INNOVATION AND TECHNOLOGY FOR ENGINEERING STUDENTS}

Abstract: This study presents and discusses the structural and formative aspects of the innovation and technology curriculum component. Through active teaching methodologies allied with Plato's Cave Myth, a work initiative in Higher Education carried out within the scope of Engineering courses. Aspects such as creativity, critical thinking and socialization were successfully developed in the proposed stages.

Keywords: Pedagogy. Teaching-learning. Philosophy. Higher education. 